We therefore question the importance Drs O'Sullivan \& Dean attach to ambivalence arising with childbirth in the pathogenesis of their patients' delusional beliefs. By their account, at least three of the four patients were, premorbidly, well adjusted individuals, and all eventually made a satisfactory recovery. No corroborating evidence is offered to support the authors' hypothesis and no allowance is made for the possibility that the content of the delusions might have been a clinical manifestation of the psychotic illness itself rather than a special clue to its aetiology. A more plausible and parsimonous explanation, at the level of both phenomenology and understanding, would be in terms of their patients' attempts to make sense of a world perceived as disturbed, thereby entering or escaping into what appears to be a delusional interpretation of events. There are important implications too, particularly if it is assumed that delusional misidentification is basically a love-hate conflict, resolved by directing ambivalent feelings to an imagined double, and that successful treatment requires the person implicated to change his or her attitude towards the patient.

Finally, the authors note the risk of violence associated with delusional misidentification. Since the reviews by Fishbain (1987) and de Pauw \& Szulecka (1988), further reports have confirmed the potential danger such patients could pose to others (e.g. Driscoll et al, 1991), including political figures (Silva et al, unpublished).

De Leo, D., Galligioni, S. \& MAGn, G. (1985) A case of Capgras delusion presenting as a postpartum psychosis. Journal of Clinical Psychiatry, 46, 242-243.

De Pauw, K. W. \& Szulecka, T. K. (1988) Dangerous delusions: violence and the misidentification syndromes. British Journal of Psychiatry, 152, 91-96.

Driscoll, R., Chithiramohan, R. \& Brockman, B. (1991) Capgras syndrome, mania and delusionally motivated assaults. Journal of Forensic Psychiatry, 2, 49-57.

FishBain, D. A. (1987) The frequency of Capgras delusions in a psychiatric emergency setting. Psychopathology, 20, 42-47.

GuzE, S. B. (1988) Psychotherapy and the etiology of psychiatric disorders. Psychiatric Developments, 3, 183-193.

Department of Psychiatry

Karel de PauW

Doncaster Royal Infirmary

Doncaster DN2 SLT

Department of Psychiatry

KRYSTYNA SZULECKA

Bassetlaw District General Hospital

Worksop S81 OBD

\section{Promoting the correct use of psychotropic drugs}

SIR: I am a physician from Pakistan and have spent 20 years with the World Health Organization
(WHO) in Geneva trying to meet WHO objectives by assisting member states in co-operation with concerned United Nations agencies in promoting efforts to obtain maximum benefit from a pharmaceutical product and to prevent any harm the substance might be capable of producing. For the last 14 years I have concentrated on psychoactive substances.

I read with great interest the letter of the late Dr John Dunne (Journal, July 1991, 159, 156). Dr Dunne concluded that, although pharmacotherapy has made a major contribution to psychiatric treatment, it does not alleviate the need for the human therapeutic process. What he tells us is that valuable drugs can be discredited by misuse. I share his views entirely.

My work in the last 14 years, as Chief of Psychotropic and Narcotic Drugs was primarily to assess the benefit and risk ratio for psychoactive substances. In addition, I investigated the role a doctor, invariably in the company of a pharmacist and a nurse, can play in promoting the rational use of these drugs. A wide-ranging analysis of what can be done to reduce the misuse of psychoactive drugs without compromising appreciation of their therapeutic value is given by Ghodse \& Khan (1988). Their book is not only to help doctors but also their other equally important partners, i.e. pharmacists and nurses. It has been translated into many other languages, as well as English and French.

Another publication, The Rational Use of Psychoactive Drugs with Special Emphasis on Tranquillizers in Psychiatric Settings by Vartainen et al (1987) is based on a meeting debating the issues of use of psychotropic drugs in general medical practice. It was evident that the majority of doctors who prescribed these drugs were not psychiatrists. It was also believed that efforts to strengthen further medical education of doctors in rational prescribing was the key to the solution of the problems associated with their use. An interaction between psychiatrists and other specialists, as well as general medical practitioners, was considered essential.

At the second regional meeting of the Royal College of Psychiatrists which met in Islamabad, Pakistan in December 1990, I raised the issue that there is a need for the College to prepare written material for the guidance of general medical practitioners who prescribe psychotropic drugs more often than psychiatrists. I was assured that the College will seriously consider this proposal.

Thus the views of the late John Dunne are valuable and need to be seriously considered in all corners of the world.

Ghodse, H. \& KHAN, I. (1988) Psychoactive Drugs: Improving Prescribing Practices. Geneva: WHO. 
Vartainen, M. E., Morozov, X. \& Khan, I. (1987) The Rational Use of Psychoactive Drugs with Special Emphasis on Tranquillizers in Psychiatric Settings (Excerpta Medica International Congress Series, 739). Amsterdam: Elsevier.

10 Chemin des Burgnons

INAYAT KHAN

\section{Meyrin}

Geneva, Switzerland

\section{Affect logic}

SIR: The current resurgence of interest in mental mechanisms and in unconscious mental processes is a healthy development in modern clinical psychiatry. It should help to redress the balance between the biological and psychological exploration of mental illness and to facilitate the correlation of psychopathology and the pathophysiology of the brain. Ciompi's erudite paper on affect and the psyche (Journal, July 1991, 159, 97-105) is a heartening addition to the literature.

The author proposes a possible basis for a new, inclusive, three-level, functional model of the psyche. Most psychiatrists would agree that human behaviour is produced by some underlying psychological structure. It is impossible, however, to infer the complete details of this mechanism and we must content ourselves with formulating more general hypotheses (Deutsch, 1962), and reconstructing the more important, albeit more abstract, design of the mechanism whose external behaviour we observe. Ciompi succeeds admirably in finding the middle road between the absurdities of the pseudopsychologist and the sterility of positivism run wild.

I was disappointed with the discussion of developmental issues and their considerable influence on the functioning of the psyche. The inner life of the mind can only be understood as a development from something more primitive in every man's behaviour. The valuable contribution of psychodynamic theory received only scant recognition despite the fact that the author was stalking mutual hunting grounds (Gottschalk, 1990). Furthermore, little was said of the role of language in general. Human beings are from the beginning recognised as potential language-users, and as potential observers of social conventions which they will later learn to formulate. The conditions of application of the vocabulary of feelings to human beings are determined by the fact that two capacities - the capacity to control their inclinations, and the capacity to identify their inclinations, and their circumstances, in words - are gradually developed together (Clark \& Clark, 1977).

Ciompi's 'new' psychosocial/biological model bears a striking resemblance to the ideas and theories expounded by the 19th-century French psychiatrist Pierre Janet (1889) and the German psychiatrist Albert Eulenberg (1878). Janet was the first to systematically study dissociation as the crucial psychological process with which the organism reacts to overwhelming experiences and show that traumatic memories may be expressed as sensory perceptions, affect states, and behavioural reenactments. Janet provided a broad framework that unifies into a larger perspective the various approaches to psychological functioning which have developed along independent lines in this century. Eulenberg believed that 'psychic shock', in the form of sudden vehement emotions such as terror or anger, could better be called psychic trauma. He regarded this 'sudden action of vehement emotions' as an actual molecular concussion of the brain, which he likened to the commotio cerebri postulated in physical trauma. Ciompi's formulation should be welcomed not as a new theory but as a rediscovery and improvement of these 19th-century contributions.

Finally, concerning the psychiatric applications of the proposed model, the author confines his discussion to possible uses in the psychoses. Potential applications in the study of the dissociation disorders, post-traumatic stress disorder and personality disorders, especially borderline states, go unmentioned. Hopefully this will be addressed in future contributions! Deutsch, J. A. (1962) The Structural Basis of Behaviour. Cambridge:
Cambridge University Press.

GotTsChaLK, L. A. (1990) The psychotherapies in the context of new developments in the neurosciences and biological psychiatry. American Journal of Psychotherapy, 44, 321-339.

CLARK, H. H. \& CLARK, E. V. (1977) Psychology and Language. New York: Harcourt Brace Jovanovich

JANET, P. (1889) L'automatisme psychologique: essai de psychologie experimentale sur les formes inferieures de l'activité humaine. Paris: Felix Alcan. (Paris: Societe Pierre Janet/Payot (1973)).

EULENBERG, A. (1878) Lehrbuch der Nervenkrankheiten, vols I, 2. Berlin: August Hirschwald.

Department of Psychological Medicine

RAY TRAVERS

Alder Hey Children's Hospital

Eaton Road

Liverpool L12 2AP

\section{Exposure therapy for PTSD}

SIR: Richards \& Rose (Journal, June 1991, 158, 836-839) describe a treatment programme for posttraumatic stress disorder (PTSD), but use outcome measures for depression, phobic anxiety and social adjustment. This is clearly a problem in PTSD 